\title{
RNPC1, an RNA-binding protein and a target of the p53 family, is required for maintaining the stability of the basal and stress-induced p21 transcript
}

\author{
Limin Shu, Wensheng Yan, and Xinbin Chen ${ }^{1}$ \\ Department of Cell Biology, The University of Alabama at Birmingham, Birmingham, Alabama 35294, USA
}

\begin{abstract}
p21, a cyclin-dependent kinase inhibitor, is transcriptionally regulated by the p53 family to induce cell cycle arrest. p21 is also regulated post-transcriptionally upon DNA damage in a p53-dependent manner, but the mechanism is uncertain. Here, we found that RNPC1, an RNA-binding protein and a target of the p53 family, is required for maintaining the stability of the basal and stress-induced p21 transcript. Specifically, we showed that RNPC1 is induced by the p53 family and DNA damage in a p53-dependent manner. The RNPC1 gene encodes at least two alternative spliced isoforms, RNPC1a and RNPC1b, both of which contain an intact RNA recognition motif. Interestingly, we found that RNPC1a, but not RNPC1b, induces cell cycle arrest in G1, although both isoforms are expressed in the nucleus and cytoplasm. In addition, we found that while both isoforms directly bind to the 3' untranslated region in p21 transcript, only RNPC1a is able to stabilize both the basal and stress-induced p21 transcripts. Conversely, RNPC1a knockdown destabilizes p21 transcript. Finally, we found that RNPC1a is required to maintain the stability of p21 transcript induced by p53.
\end{abstract}

[Keywords: RNPC1; p21; p53; p53 family; transcriptional regulation; cell cycle]

Supplemental material is available at http://www.genesdev.org.

Received June 26, 2006; revised version accepted September 12, 2006.

Mutations of p53 tumor suppressor occur in $>50 \%$ of human cancer, and loss of p53 function is known to play a central role in cancer development (Vogelstein et al. 2000). The importance of p53 in this process is underscored by the ability of p53 as a transcription factor (Ko and Prives 1996). Upon activation, p53 induces a number of genes (Harms et al. 2004), such as p21(WAF1/CIP1) (el-Deiry et al. 1993), MDM2 (Barak et al. 1993; Wu et al. 1993), IGFBP3 (Buckbinder et al. 1995; Harms and Chen 2005), PIDD (Lin et al. 2000), and Killer/DR5 (Wu et al. 1997), which mediate the diverse biological functions of p53, including cell cycle arrest and apoptosis (Vousden and $\mathrm{Lu} \mathrm{2002).}$

RNA-binding proteins have been shown to post-transcriptionally regulate gene expression, such as polyadenylation, RNA splicing, transport, stability, and translation, all of which are emerging as critical mechanisms for gene regulation in mammalian cells (Krecic and Swanson 1999). In addition, an increasing number of RNA-binding proteins have been identified and found to be altered in a variety of genetic disorders, such as fragile

${ }^{1}$ Corresponding author.

E-MAIL xchen@uab.edu; FAX (205) 934-0950.

Article published online ahead of print. Article and publication date are online at http://www.genesdev.org/cgi/doi/10.1101/gad.1463306.
$\mathrm{X}$ mental retardation and myotonic dystrophy (Siomi et al. 1993; Timchenko et al. 1996). In general, RNA-binding proteins contains one or more RNA-binding motifs, such as RNA recognition motif (RRM), hnRNP K homology motif, RGG box, and dsRBD motif (Dreyfuss et al. 1993, 2002; Krecic and Swanson 1999). Among these RNA-binding motifs, RRM is the most prevalent type of eukaryotic RNA-binding motifs (Dreyfuss et al. 1993). RRM is composed of two submotifs, RNP1 and RNP2 (Dreyfuss et al. 1993). Among the RRM-containing proteins are the Elav-like RNA-binding protein family (Myer et al. 1997), which consist of $\mathrm{HuB}, \mathrm{HuC}, \mathrm{HuD}$, and HuR (Gorospe 2003).

p21 is shown to be the major mediator of p53 to regulate the cell cycle transition from G1 to S (el-Deiry et al. 1993; Harper et al. 1993; Xiong et al. 1993). p21 is also regulated by other p53 family proteins; that is, p63 and p73 (Kaghad et al. 1997; Yang et al. 1998; Zhu et al. 1998). In addition to the transcriptional regulation by the p53 family, the level of p21 is found to be regulated by post-transcriptional mechanisms. For example, the stability of p21 transcript is found to be increased in cells irradiated with ultraviolet C (UVC) in a p53-dependent manner (Gorospe et al. 1998) and in cells treated with various agents, such as tumor necrosis factor $\alpha$ (Shiohara et al. 1996), epidermal growth factor (EGF) (Giles et al. 
2003), prostaglandin A2 (Gorospe and Holbrook 1996), and phorbol myristate acetate (Liu et al. 1996). Upon exposure to UVC or treatment with EGF and prostaglandin $\mathrm{A} 2, \mathrm{HuR}$ is translocated from nucleus to cytosol, which binds to the $3^{\prime}$ untranslated region (UTR) in p21 transcript and enhances its stability (Wang et al. 2000; Giles et al. 2003; Yang et al. 2004). Interestingly, the subcellular shuttling of HuR protein following UVC irradiation is p53 independent (Wang et al. 2000). Similarly, $\mathrm{HuD}$, a neuronal member of the Elav-like family, is necessary for nerve growth factor-mediated neural differentiation, binds to and stabilizes p21 transcript (Joseph et al. 1998). Recently, Msi-1, a member of the musashi RNA-binding protein family, is found to repress p21 translation via directly binding to $\mathrm{p} 21$ transcript (Battelli et al. 2006).

Here we presented evidence that the RNPC1 gene, which encodes at least two isoforms of an RNA-binding protein through alternate splicing at the $\mathrm{C}$ terminus, is induced by the p53 family and by DNA damage in a p53-dependent manner. While both isoforms contain one RRM motif and bind to the 3' UTR in p21 transcript, the large isoform, RNPCla, is capable of inducing G1 arrest and regulating the stability of p21 transcript. Furthermore, we provided evidence that RNPCla is required for the maintenance of the stability of p21 transcript induced by $\mathrm{p} 53$. Together, we concluded that RNPC1 is a target of the p53 family and serves as a mediator of the p53 family to regulate p21 post-transcriptionally.

\section{Results}

\section{RNPC1 is a direct target of the p53 family}

p21 is known to be regulated by the p53 family, and serves as a major mediator of the family to induce cell cycle arrest in G1. However, it is possible that other genes that are regulated by the p53 family participate in such a process. To do this, we performed a microarray study to identify potential common target genes for the p53 family. Among the genes up-regulated by various p53 family proteins in MCF7 cells, RNPC1 appears to be a common target of the p53 family (Chen et al. 2003). To further address this, Northern blot analysis was performed. We showed that RNPC1 was induced by wildtype p53 but not mutant p53(R249S) in both MCF7 and H1299 cells (Fig. 1A). The induction of p21 was measured as a positive control and the level of glyceraldehyde-3-phosphate dehydrogenase (GAPDH) measured as a loading control. Similarly, RNPC1 was induced by p $63 \gamma, \Delta \mathrm{Np} 63 \alpha$, and p $73 \beta$ in both MCF7 and $\mathrm{H} 1299$ cells (Supplementary Fig. 1A).

DNA damage stabilizes and activates p53, leading to induction of p53 target genes. We reasoned that RNPC1, as a p53 target gene, is likely to be induced by DNA damage in cells that carry an endogenous wild-type p53 gene. To this end, we used RKO, HCT116, and MCF7 cell lines in which endogenous p53 is wild-type. We also used RKO-p53-KD and HCT116(p53-/-), in which endog-
A

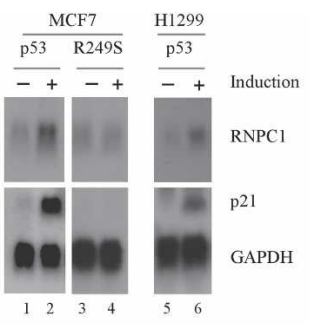

B

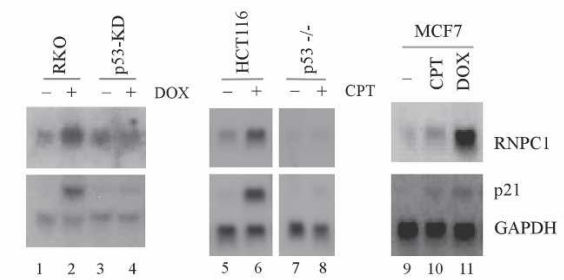

C

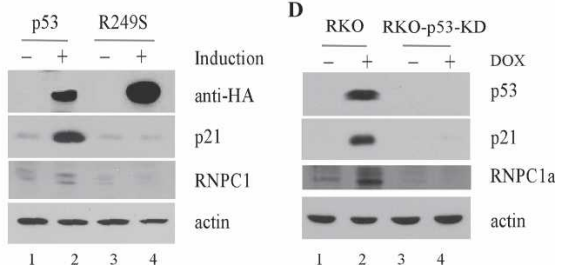

Figure 1. RNPC1 is induced by p53. (A) Northern blots were prepared with RNAs purified from MCF7 and H1299 cells that were uninduced $(-)$ or induced $(+)$ to express p53 or p53(R249S). The blots were probed with cDNAs derived form the RNPC1, p21, and GAPDH genes, respectively. (B) Northern blots were prepared with RNAs purified from RKO, RKO-p53-KD, HCT116, HCT116(p53-l-), and MCF7 cells that were mocktreated $(-)$ or treated $(+)$ with $0.4 \mu \mathrm{g} / \mathrm{mL}$ doxorubincin $(\mathrm{DOX})$ or $300 \mathrm{nM}$ camptothecin (CPT) for $20 \mathrm{~h}$. The blots were analyzed as in $A$. $(C, D)$ Western blots were prepared using extracts from MCF7 cells that were uninduced $(-)$ or induced $(+)$ to express HA-tagged wild-type p53 or p53(R249S) or extracts from RKO or RKO-p53-KD cells that were untreated $(-)$ or treated $(+)$ with 0.4 $\mu \mathrm{g} / \mathrm{mL}$ doxorubincin (DOX). HA-tagged wild-type p53 and p53(R249S) in MCF7 cells were detected by anti-HA and endogenous p53 in RKO cells detected by anti-p53 monoclonal antibodies. p21, RNPC1, and actin were detected by their respective antibodies.

enous wild-type p53 was knocked down and knocked out, respectively (Bunz et al. 1998; Liu and Chen 2006). We found that RNPC1 was induced in RKO, HCT116, and MCF7 cells treated with DNA-damaging agent doxorubicin or camptothecin (Fig. 1B, RNPC1 panel). Similarly, p21 was induced (Fig. 1B, p21 panel). However, little if any induction of RNPC1 and p21 was detected in RKO-p53-KD and HCT116(p53 $\left.3^{-/-}\right)$cells treated with doxorubicin or camptothecin (Fig. 1B).

Next, we determined whether an increase in RNPC1 transcript correlates with an increase in RNPC1 protein. RNPC1 is expressed as at least two alternative spliced isoforms, RNPCla and RNPC1b. Polyclonal antibody against histidine-tagged RNPC1 fusion proteins was made in rabbits and found to recognize HA-tagged RNPCla, but not HA-tagged RNPC1b (Supplementary Fig. 1B). We found that the level of RNPC1a was signifi- 
cantly increased in MCF7 cells by wild-type, but not mutant, p53(R249S) (Fig. 1C, cf. lanes 2,4 and 1,3, respectively) and in RKO cells treated with doxorubicin in a p53-dependent manner (Fig. 1D, cf. lanes 2,4 and 1,3, respectively). Levels of $\mathrm{p} 21$ were measured as a positive control, whereas levels of actin measured as a loading control. Similarly, we found that the levels of RNPCla were increased in MCF7 cells by $\mathrm{p} 63 \alpha, \Delta \mathrm{Np} 63 \alpha, \mathrm{p} 63 \gamma$, $\mathrm{p} 73 \beta$, and $\Delta \mathrm{Np} 73 \beta$, but not $\Delta \mathrm{Np} 63 \gamma$ (Supplementary Fig. 1C). To make certain that RNPC1b is induced by the p53 family, RT-PCR was performed and showed that the levels of RNPC1b transcript were increased by p53, p63 $\gamma$, p73 $\beta$, and $\Delta$ Np $73 \beta$ (Supplementary Fig. 1D).

p53 transactivates its target gene through binding to specific DNA sequences in the promoter or intron. Thus, we searched for p53-responsive elements (p53REs) in the genomic locus encoding the RNPC1 gene and found two potential binding sites: one located at nucleotides -3351 to -3330 in the promoter with the sequence of AGCCTGGCTCCCAGCCTAGTCT, disignated as p53RE-1; and the other located at nucleotides +519 to +546 in intron 1 with the sequence of GGGCAAGTC CAGGCGGCCCCCCAAGCTC, disignated as p53RE-2. Upon alignment with the consensus p53RE (el-Deiry et al. 1992), we found three mismatches each in both p53RE-1 and p53RE-2 (Fig. 2A, top panel; lowercase letters represent mismatches).

To examine p53RE-1, we cloned a promoter fragment containing p53RE-1 from nucleotides -3424 to +85 and a shorter fragment lacking p53RE-1 from nucleotides -1215 to +85 into pGL2 luciferase reporter, respectively (Fig. 2A, bottom panel at the left). We found that p53 was able to increase the luciferase activity under the control of the RNPC1 promoter fragment from nucleotides -3424 to +85 , but not under the control of the promoter fragment lacking the potential p53RE-1 from nucleotides -1215 to +85 (Fig. 2B). In contrast, mutant p53(R249S) was inert (Fig. 2B). Similarly, the RNPC1 promoter containing p53RE-1 was responsive to $\mathrm{p} 63 \alpha, \Delta \mathrm{Np} 63 \alpha, \mathrm{p} 63 \gamma$, $\Delta \mathrm{Np} 63 \gamma, \mathrm{p} 73 \beta$, and $\Delta \mathrm{Np} 73 \beta$ (Supplementary Fig. $2 \mathrm{~A}$ ).

To examine p53RE-2, a 379-base-pair (bp) fragment (nucleotides +373 to +751 ) from intron 1 (Fig. 2A, bottom panel at the right) was cloned upstream of the minimal c-fos promoter and a luciferase reporter in O-Fluc (Johansen and Prywes 1994). In addition, a deletion mutant $(\Delta 520-546)$ that deletes the entire p53RE-2 and a point mutant (C522A) that alters one of the critical nucleotides in p53RE-2 were also cloned into O-Fluc (Fig. 2A). We showed that the luciferase activity under the control of the fragment $+373 /+751$, but not the deletion mutant ( $\Delta 520-546)$ or point mutant (C522A), was substantially increased by wild-type p53, p63 $\alpha$, p63 $\gamma$, and p $73 \beta$, and little, if any, by mutant p53(R249S) (Fig. 2C; Supplementary Fig. 2B, respectively).

To further analyze p53RE-1 and p53RE-2 in the RNPC1 gene, we performed chromatin immunoprecipitation (ChIP) assay with primers shown in Figure $2 \mathrm{D}$. The binding of the p53 family proteins to p53RE- 1 in the p21 promoter was also determined as a positive control (Fig. 2D). To analyze the binding of p53, RKO cells were
A

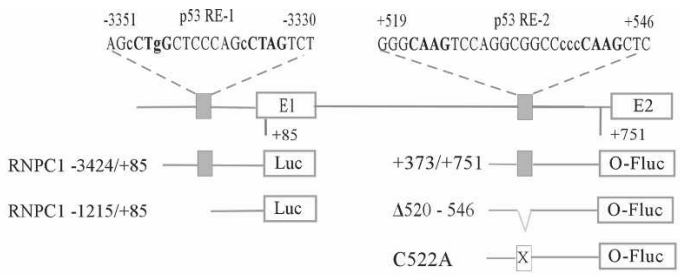

B
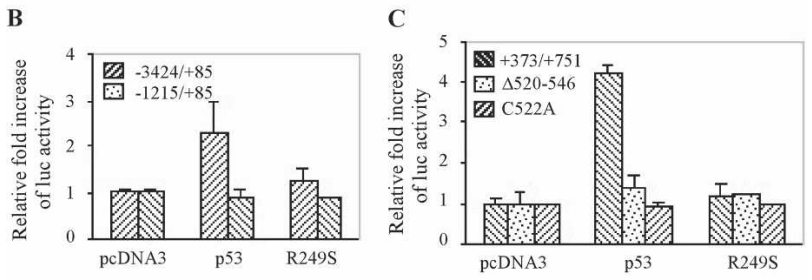

D

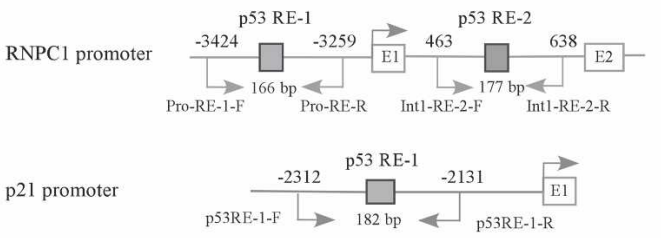

E

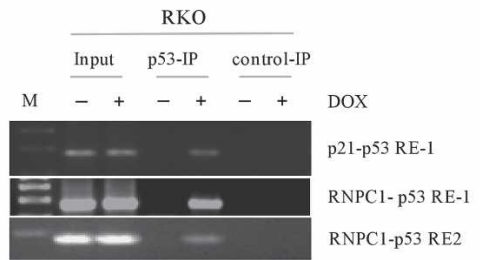

Figure 2. Identification of potential p53REs in the RNPC1 gene. (A) Schematic presentation of the RNPC1 locus and luciferase reporter constructs along with two potential p53REs located in the promoter and intron I (p53RE-1 and p53RE-2). (B,C) The p53REs in the RNPC1 gene are responsive to p53 but not mutant p53(R249S). The luciferase assay was performed as described in Materials and Methods. $(D)$ Schematic presentation of the RNPC1 promoter, intron 1 , and the $\mathrm{p} 21$ promoter with the location of the p53REs and PCR primers used for ChIP assay. $(E)$ p53 binds directly to the p53REs in the RNPC1 and p 11 genes in vivo. ChIP assay was performed as described in Materials and Methods.

untreated $(-)$ or treated $(+)$ with doxorubicin to activate p53 followed by cross-linking with formaldehyde and immunoprecipitation with anti-p53 antibody or anti-HA antibody as a control. We found that p53 bound to both p53RE-1 and p53RE-2 in the RNPC1 gene as well as to p53RE-1 in the p21 gene (Fig. 2E). To analyze the binding of p63 or p73, MCF7 cells were uninduced $(-)$ or induced $(+)$ to express Myc-tagged p63 $\gamma$ or HA-tagged p73 $\beta$ and then used for ChIP assay. The p63-DNA complexes were immunoprecipitated with anti-Myc antibody along with anti-HA as a control. The p73-DNA complexes were immunoprecipitated with anti-HA antibody along with anti-Myc as a control. We found that both $\mathrm{p} 63 \gamma$ and $\mathrm{p} 73 \beta$ bound to p53RE-1 and p53RE-2 in the RNPC1 gene as well as to p53RE-1 in the p21 gene (Supplementary Fig. 
Shu et al.

2C). In sum, these data suggest that RNPC1 is likely to be a direct target of the p53 family.

\section{RNPC1 is an RNA-binding protein}

According to the published sequence /GenBank \#BC018711), the RNPC1 gene encodes two RNPC1 isoforms, designated RNPCla with 239 amino acids and RNPC1b with 121 amino acids (Fig. 3A; Supplementary Fig. 3A). The sequence in RNPC1b is identical to the $\mathrm{N}$-terminal region in RNPC1a. Both isoforms contain a canonical RRM (amino acids 35-107) (Supplementary Fig. 3A). Sequence alignment of RRMs among RNPC1 and other RRM-containing proteins indicated that the two submotifs, RNP-1 and RNP-2, are highly conserved, matching all the consensus residues (Supplementary Fig. 3A). The phylogenic analysis showed that RNPC1 belongs to a family of RNA-binding proteins that consists of musashi, HuR, U2AF65, and nucleolin (Supplementary Fig. 3B).

\section{Intracellular localization of RNPC1}

As an RNA-binding protein, RNPC1 may be shuttling in and out of the nucleus along with its cargos, RNA transcripts. To test this, immunofluorescence microscopy was performed with an anti-RNPC1 antibody and showed that endogenous RNPC1 was primarily localized in the cytosol, but a minute amount of it was also detected in the nucleus (Supplementary Fig. 4A, top panel). To determine the cellular localization of RNPCla and RNPC1b, both isoforms were HA-tagged at the $\mathrm{N}$ termi- nus, which was then inducibly expressed in RKO cells under the control of a tetracycline-inducible promoter. Two representative cell lines each that can inducibly express HA-tagged RNPCla or RNPC1b were shown in Figure 3B. Immunofluorescence microscopy showed that like endogenous RNPC1, RNPC1a and RNPC1b were localized primarily in the perinuclear membrance and/or cytosol (Supplementary Fig. 4A, middle and bottom panels). To further confirm this, whole-cell extracts and extracts from the cytosol and nucleus were prepared in RKO cells inducibly expressing HA-RNPC1a or HARNPC1b. Consistent with the immunofluorescence assay, both RNPC1a and RNPC1b were expressed in both the cytosol and nucleus (Supplementary Fig. 4B). However, the fraction of RNPC1b in the cytosol was more than that in the nucleus (Supplementary Fig. 4B, cf. lanes 8 and 12).

\section{RNPC1a is capable of inducing cell cycle arrest when overexpressed}

To determine the biological activity of RNPC1, RKO cell lines that inducibly express either RNPC1a or RNPC1b (Fig. 3B) were used for growth rate analysis. We found that cell proliferation was suppressed by RNPC1a, but not RNPC1b, over a 6-d testing period (Fig. 3C,E). Next, to determine whether the growth suppression is due to cell cycle arrest, apoptosis, or both, DNA histogram analysis was performed. We showed that cells were arrested primarily in G1 by RNPC1a (Fig. 3D), but not by RNPC1b (Fig. 3F).

To rule out the possibility that the effect of RNPC1a is cell type specific, we generated MCF7, HCT116,
Figure 3. Overexpression of RNPCla, but not RNPC1b, inhibits cell proliferation and induces cell cycle arrest in G1. (A) Schematic presentations of the RNPC1 locus and the usage of exons for RNPCla and RNPC1b. (B) Generation of RKO cell lines that inducibly express HA-tagged RNPC1a or RNPC1b. The levels of HA-RNPC1a and RNPC1b were quantified with anti-HA. $(C, E)$ The growth rate of RKO cells that were uninduced or induced to express HA-tagged RNPCla $(C)$ or RNPC1b $(E)$ was measured over a 6-d period. $(D, F)$ RKO cells were uninduced $(-)$ or induced $(+)$ to express HA-RNPC1a or HA-RNPC1b for 2 or $4 \mathrm{~d}$ and then stained with propidium iodide for DNA histogram analysis as described in Materials and Methods.
A

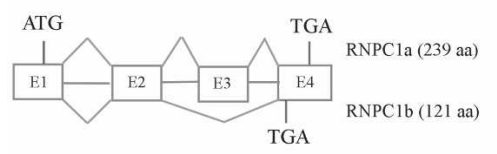

B
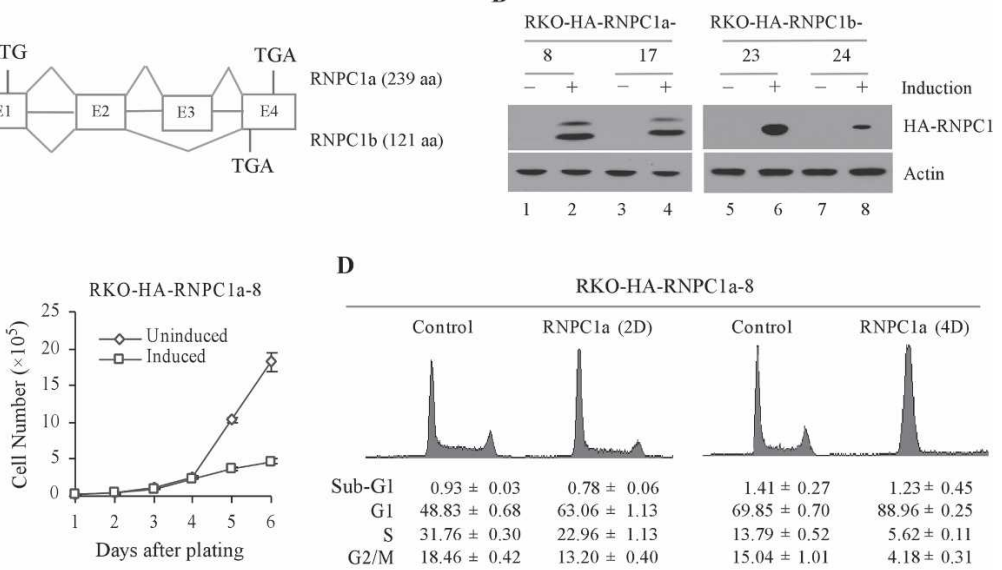

D

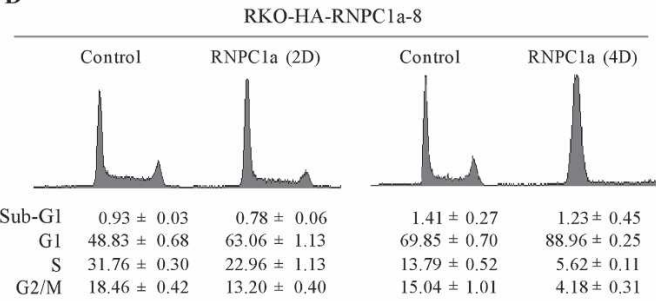

E

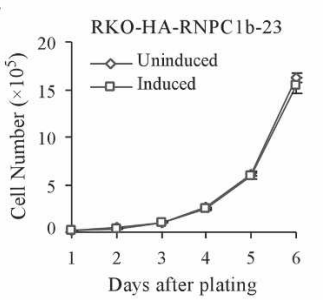

F

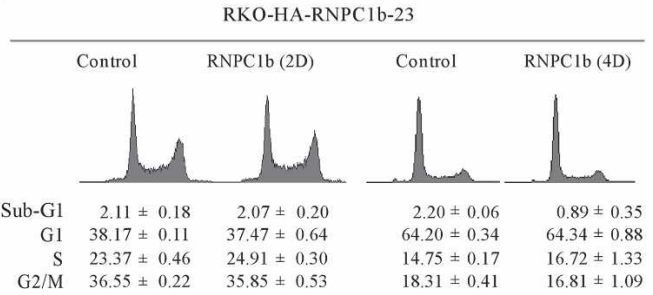




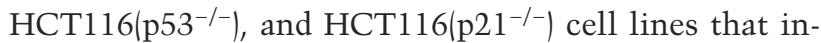
ducibly express HA-tagged RNPCla (Fig. 4A,D,F,H). We showed that cell proliferation was inhibited by RNPC1a in MCF7 and HCT116 cell lines (Fig. 4B,E). In addition, we showed that RNPCla was able to suppress cell proliferation in p53- and p21-independent manners, since p53 and p21 were somatically knocked out in

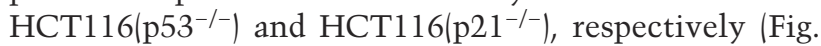
4G,II. Furthermore, DNA histogram analysis showed
A

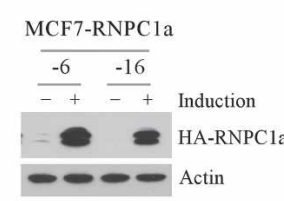

C

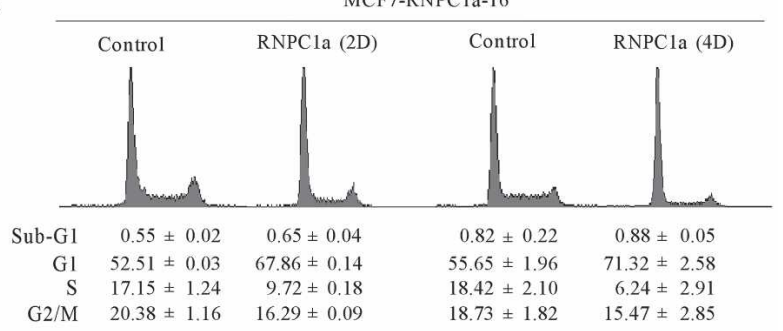

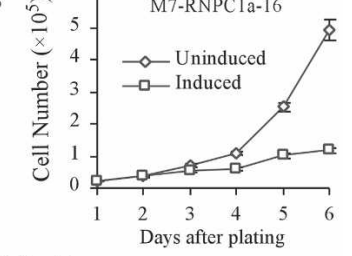

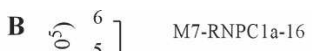

D

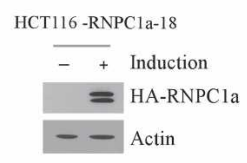

F

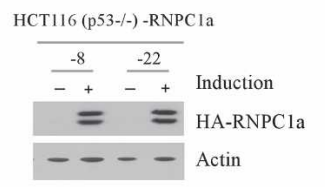

H
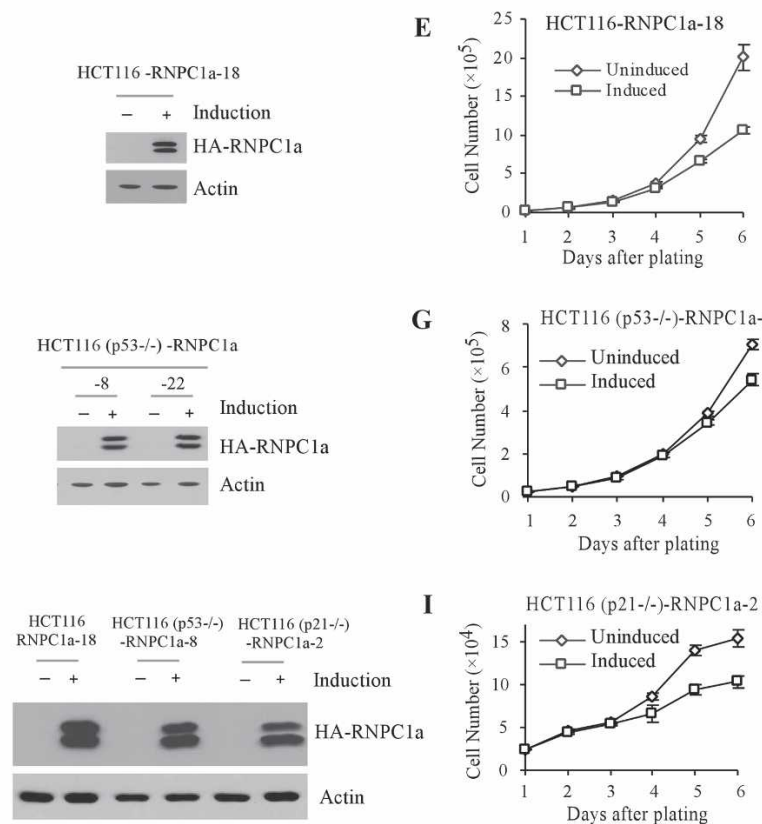

G

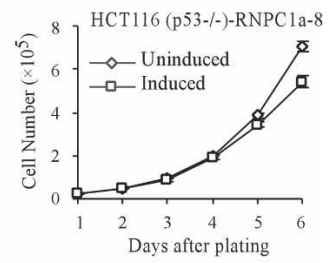

I

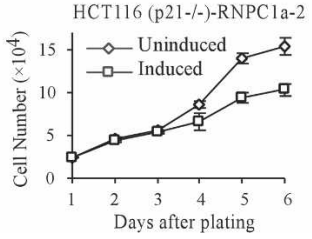

Figure 4. RNPCla-mediated growth suppression is not cell type specific, and can be independent of $\mathrm{p} 53$ and p21. $(A, D, F, H)$ Generation of MCF7, HCT116, HCT116(p53-l- ), and HCT116(p21 $1^{-/-}$) cell lines that inducibly express HA-RNPC1a. The level of HA-RNPCla was quantified with anti-HA. (B,E,G,I) The growth rate of MCF7, HCT116, HCT116(p53 $3^{-/-}$, and HCT116(p21 $\left.1^{-I-}\right)$ cells that were uninduced or induced to express HA-RNPC1a was measured over a 6-d period. (C) MCF7 cells were uninduced $(-)$ or induced $(+)$ to express HA-RNPC1a for 2 or $4 \mathrm{~d}$ and then stained with propidium iodide for DNA histogram analysis. that MCF7 cells were arrested in G1 upon induction of RNPC1a (Fig. 4C).

\section{RNPC1 directly binds to $221 \mathrm{mRNA}$ and enhances its stability}

As an RNA-binding protein, RNPC1 is likely to exert its activity by regulating the function of a protein directly involved in the cell cycle regulation. Since p21 is the most well-defined mediator of the p53 family in G1 arrest, we explored the possibility that the function of RNPCla is linked to that of $\mathrm{p} 21$. Thus, we performed Western blot analysis and showed that the level of p21 protein was significantly increased in RKO cells upon induction of RNPCla in a time-dependent manner (Fig. 5A, p21 panel, cf. lanes 1,3,5,7 and 2,4,6,8, respectively). Similarly, the level of p21 was markedly increased in MCF7, HCT116, and HCT116(p53-/-) cells upon induction of RNPC1a (Fig. 5B,C, p21 panels). However, RNPC1b had no effect on the level of p21 (Fig. 5D, p21 panel, cf. lanes $1,3,5,7$ and 2,4,6,8, respectively). These data suggest that the effect of RNPC1a on p21 is not cell type specific. We also examined several other proteins, such as p53, PCNA, and p27 and found that none of these proteins were significantly affected (Fig. 5A-C).

To determine whether RNPCla is able to further increase the extent of p53 induction of p21, the level of p21 was examined in RKO cells uninduced (-) or induced $(+)$ to express RNPCla for $3 \mathrm{~d}$ along with treatment of 0.4 $\mu \mathrm{g} / \mathrm{mL}$ doxorubicin (Fig. 5E) or $5 \mu \mathrm{M}$ Nutlin-3 (Fig. $5 \mathrm{~F}$ ) for $0,4,8,12$, or $24 \mathrm{~h}$. Nutlin is an inhibitor of Mdm2, which activates p53 without causing DNA damage (Vassilev et al. 2004). We showed that RNPCla was expressed upon induction (Fig. 5E,F, RNPC1 panel), whereas p53 was accumulated upon treatment with $0.4 \mu \mathrm{g} / \mathrm{mL}$ of doxorubicin within $8 \mathrm{~h}$ (Fig. 5E, p53 panel) or $5 \mu \mathrm{M}$ Nutlin within $4 \mathrm{~h}$ (Fig. 5F, p53 panel). Interestingly, the levels of p21, but not mdm2, were further increased by RNPC1a, although both $\mathrm{p} 21$ and $\mathrm{mdm} 2$ were induced upon p53 activation (Fig. 5E,F, p21 and $\mathrm{mdm} 2$ panels).

As an RNA-binding protein, RNPC1 may directly bind to p21 mRNA and then increase its stability. Thus, Northern blot analysis was performed and showed that the levels of p21 were increased in RKO cells upon induction of RNPCla in a time-dependent manner (Fig. $6 \mathrm{~A}, \mathrm{p} 21$ panel). To further test this, an RNA immunoprecipitation assay was performed using extracts from RKO cells that transiently express HA-RNPCla, HARNPCla (F37S), or HA-RNPC1b. RNPCla (F37S) carries a serine instead of phenylalanine at codon 37 , which is located in the RNP2 submotif of the RRM and predicted to be critical for RNA binding (Supplementary Fig. 3A). Western blot analysis showed that all the proteins were expressed in RKO cells (Fig. 6B). Next, an anti-HA antibody was used to immunoprecipitate potential RNPC1RNA complexes, whereas an anti-Flag antibody was used as control. The precipitated RNPC1-RNA complexes were treated with RNase-free DNase to remove trapped genomic DNAs, and then the pull-down RNAs were purified by Trizol reagent for cDNA synthesis. Five per- 
Shu et al.

Figure 5. RNPC1a increases the level of p21 expression in multiple cell types, which can be independent of p53. $(A-C)$ The level of $\mathrm{p} 21$ protein is increased by RNPCla. Western blots were prepared using cell extracts from RKO $(A)$, MCF7 (B), HCT116 (C, lanes 1-8), and HCT116(p53 $\left.3^{-/-}\right)(C$, lanes 9-16) that were uninduced $(-)$ or induced $(+)$ to express HARNPC1a for 12-72 h. HA-RNPC1a, p21, p53, p27, PCNA, and actin were quantified with anti-HA, anti-p21, anti-p53, anti-p27, antiPCNA, and anti-actin, respectively. $(D)$ RNPC1b has no effect on the level of p21 protein. The experiment was performed as in $A-C$ except that RKO cells were uninduced or induced to express HA-RNPC1b. $(E, F)$ The levels of $\mathrm{p} 21$ protein induced by p53 are further increased by RNPCla. Western blots were prepared with extracts from RKO cells uninduced $(-)$ or induced $(+)$ to express RNPC1 for $3 \mathrm{~d}$ along with treatment of 0.4 $\mu \mathrm{g} / \mathrm{mL}$ doxorubicin $(E)$ or $5 \mu \mathrm{M}$ Nutlin $(F)$ for $0,4,8,12$, or 24 h. HA-RNPC1a, p21, p53, $\mathrm{mdm} 2$, and actin were quantified with antiHA, anti-p21, anti-p53, anti-mdm2, and antiactin, respectively.
A

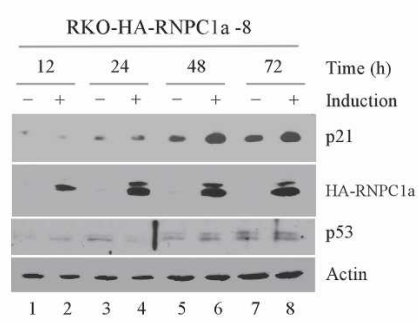

B

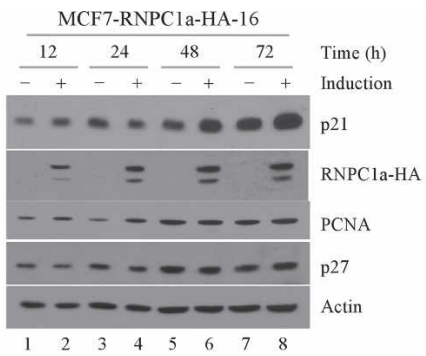

C

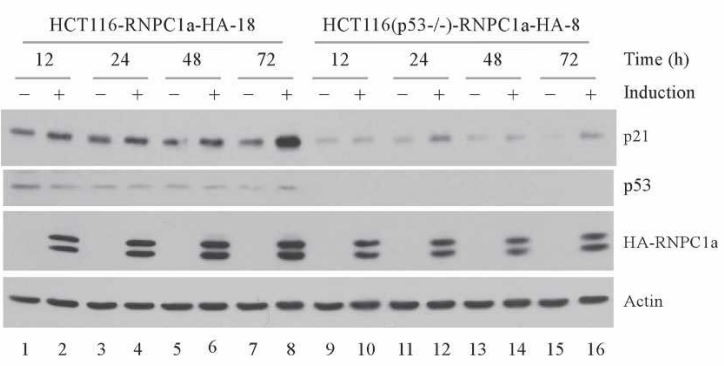

D

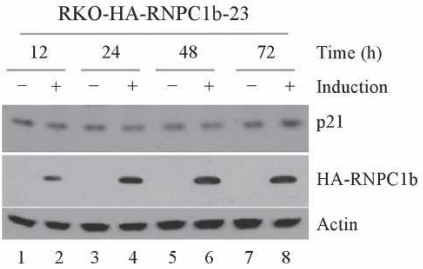

$\mathbf{E}$

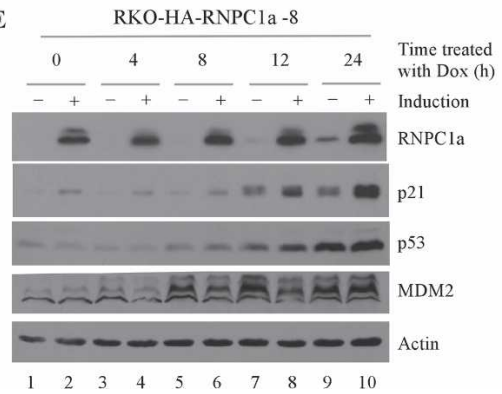

F

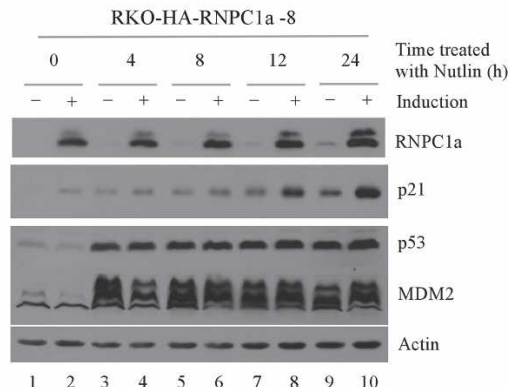

cent of cell extracts were used directly for RNA extraction as an input control. Upon RT-PCR amplification, p21 transcripts were found to associate with RNPC1a and RNPC1b, but not RNPC1a (F37S) (Fig. 6C, HA-IP panel). No p21 transcripts were found to be immunoprecipitated by control anti-Flag antibody (Fig. 6C, Flag-IP panel). In addition, GAPDH transcripts were not found to interact with RNPC1 (Fig. 6C, GAPDH column).

Next, we wanted to identify the region in p21 transcript that is responsive to RNPC1a. To test this, we performed a luciferase assay using pGL3 reporter that contains various regions from the $3^{\prime}$ UTR in the p21 transcript (Fig. 6D, left column; Giles et al. 2003). We found that upon cotransfection with RNPC1a, a significant increase of luciferase activity was observed for pGL3-1/7, pGL3-2/7, and pGL3-6/7, but not for the control pGL3, pGL3-1/6 and pGL3-1215 (Fig. 6D, right column). These data suggest that p21 mRNA stability is likely controlled via a potential cis-element located within nucleotides $879-1512$ in the $3^{\prime}$ UTR in p21 tran- script, but not the previously identified AU-rich region within nucleotides 571-829 bound by HuR and HuD (Joseph et al. 1998; Wang et al. 2000; Giles et al. 2003; Yang et al. 2004) or GTAGT within nucleotides 1819-1823 bound by Msi (Battelli et al. 2006).

To further explore how RNPC1a increases the level of p21 mRNA, Northern blot analysis was performed to measure the decay rate of $\mathrm{p} 21$ transcript in the presence or absence of RNPC1a. Upon inhibition of new RNA synthesis with actinomycin D, the relative half-life for p21 mRNA was more than doubled by RNPC1a from $\sim 2.5$ to $5.3 \mathrm{~h}$ (Fig. 6E,F).

\section{RNPC1 is required for maintaining the stability of the basal and stress-induced p21 mRNA}

To demonstrate the physiological relevance for the regulation of $\mathrm{p} 21$ by RNPC1a, we generated MCF7 cell lines in which endogenous RNPCla can be inducibly knocked down. Two representative cell lines were shown in Fig- 
A

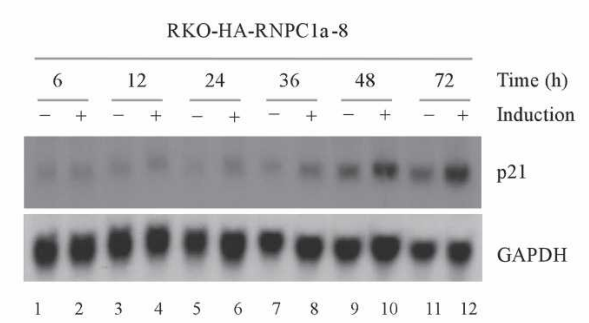

B

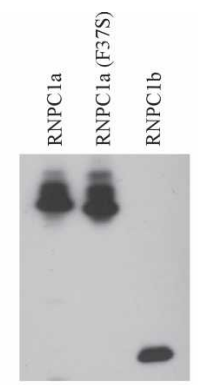

C

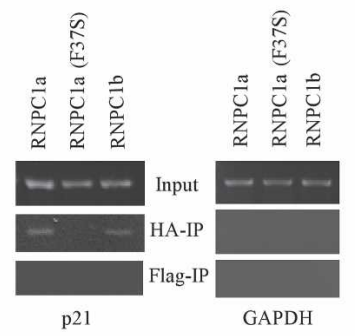

D

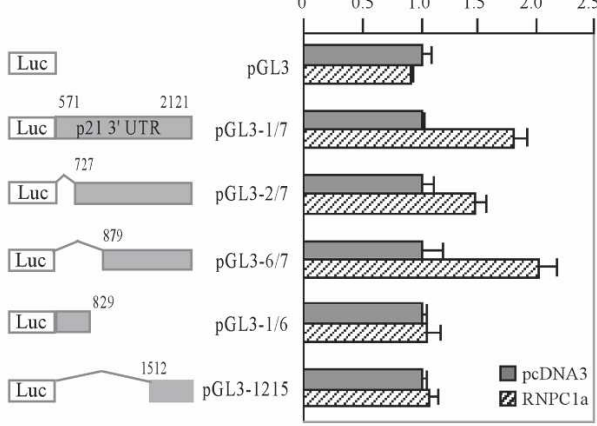

E

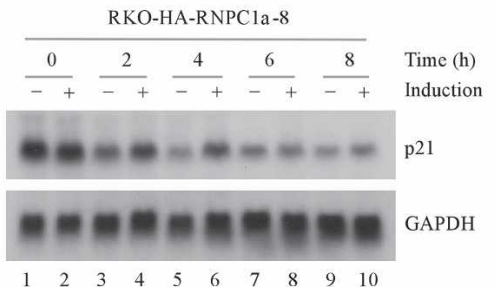

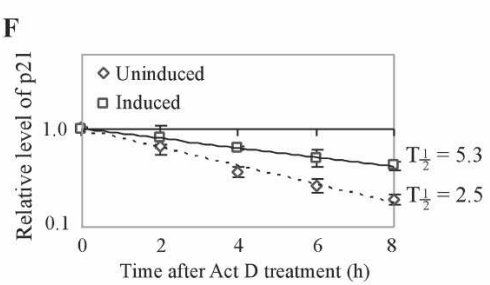

Figure 6. RNPC1 directly binds to the $3^{\prime}$ UTR in p21 transcript and enhances p 21 mRNA stability. (A) RNPC1a increases the level of p21 mRNA. Northern blots were prepared using RNAs purified from RKO cells that were uninduced $(-)$ or induced $(+)$ to express HA-RNPCla for 6-72 h. The blots were probed with cDNAs derived from p21 and GAPDH, respectively. $(B)$ Expression of HA-RNPC1a, HA-RNPC1a (F37S), and HA-RNPC1b. A Western blot was prepared using extracts from RKO cells that were transiently transfected with a pcDNA3 vector expressing HA-RNPC1a, HA-RNPC1a (F37S), or HA-RNPC1b. The blot was probed with antiHA. (C) HA-RNPC1a and HA-RNPC1b, but not HA-RNPC1a (F37S), bind directly to p21, but not GAPDH, transcripts. p21 and GAPDH transcripts were detected by RT-PCR from potential RNPC1-p21 mRNA complexes immunoprecipitated with anti-HA, or a control complex immunoprecipitated with anti-Flag as described in Materials and Methods. (D) The 3' UTR between nucleotide 879 and 1512 in the p21 transcript is responsive to RNPCla. H1299 cells were cotransfected with $200 \mathrm{ng}$ of pGL3 control reporter or pGL3 reporter carrying various regions from the 3' UTR in p21 transcript along with empty pcDNA3 or pcDNA3 expressing HA-RNPCla. Luciferase assay was carried out as described in Materials and Methods. (E) The half-life of p21 transcript is enhanced by RNPC1a. The levels of p21 and GAPDH transcripts were measured by Northern blot analysis using RNAs purified from RKO cells that were uninduced $(-)$ or induced $(+)$ to express HA-RNPCla for $20 \mathrm{~h}$, followed by treatment with $7.5 \mu \mathrm{g} / \mathrm{mL}$ of actinomycin D (Act D) for 0, 2, 4, 6, or $8 \mathrm{~h} .(F)$ The relative half-life of p21 transcript in the absence or presence of RNPC1a. Upon normalization with the level of GAPDH transcript, the relative half-life of p21 transcript was calculated from three separate experiments.

ure 7A. Upon induction of small interfering RNA (siRNA) against RNPC1a for 2 or $3 \mathrm{~d}$, the levels of RNPCla transcript were markedly reduced and the levels of p21 transcript were concomitantly decreased (Fig. 7A, RNPC1a and p21 panels, cf. lanes 1,3,5,7 and 2,4,6,8, respectively). Next, we examined the decay rate of $\mathrm{p} 21$ transcript and found that the relative half-life for $\mathrm{p} 21$ mRNA was decreaed from $\sim 2.7$ to $\sim 2.2 \mathrm{~h}$ (Fig. $7 \mathrm{~B}, \mathrm{C}$ ). We also examined the levels of $\mathrm{p} 21$ protein upon knockdown of RNPC1a for 24-72 h. We found that the levels of $\mathrm{p} 21$ protein, but not p53 and Mdm2, were decreased (Fig. 7D, cf. lanes 1,3,5 and 2,4,6, respectively). These data indicated that the stability of p21 transcript at a normal condition is controlled by RNPC1a.

Since p53 induction of p21 is enhanced by overexpression of RNPCla (Fig. 4E,F), we wanted to determine whether $\mathrm{p} 53$ induction of $\mathrm{p} 21$ is attenuated by RNPC1a knockdown. To test this, two representative MCF7 clones (\#36 and \#62) were treated with doxorubicin, Nutlin, and camptothecin for $0-12 \mathrm{~h}$ in the presence or absence of RNPC1a knockdown. We found that p53 accumulation was detected upon treatment with doxorubicin, Nutlin, and camptothecin, regardless of the status of
RNPCla knockdown (Fig. 7E-G; Supplementary Fig. 5A,B, p53 panels). However, upon treatment with Nutlin and camptothecin, p53 accumulation in one MCF7 clone (\#36) was slightly attenuated in the absence of RNPC1a within the first $3 \mathrm{~h}$, but not at the later time points (Fig. 7F,G, p53 panels, cf. lanes 3 and 4). Nevertheless, while p21 was increased following p53 accumulation, the extent of the p21 increase was substantially less in the presence of RNPC1a knockdown than in the absence of RNPCla knockdown during the testing period (Fig. 7EG; Supplementary Fig. 5A,B, p21 panels, cf. lanes 6,8,10 and 5,7,9, respectively). Interestingly, p53 induction of $\mathrm{Mdm} 2$ and $\mathrm{PolH}$, both of which are regulated by $\mathrm{p} 53$ (Barak et al. 1993; Wu et al. 1993; Liu and Chen 2006), was not substantially affected by RNPCla knockdown (Fig. 7E-G; Supplementary Fig. 5A,B, Mdm2 and PolH panels). Taken together, these data suggest that RNPC1a is required for maintaining the stability of p21 induced by $\mathrm{p} 53$.

\section{Discussion}

Many p53 family target genes have been identified, but to our knowledge, RNPC1 is the only common p53 fam- 
Shu et al.

Figure 7. RNPC1 is required for maintaining the stability of the basal and stress-induced p21 mRNA. (A) Generation of two MCF7 cell lines in which endogenous RNPCla is inducibly knocked down using a tetracycline-inducible H1 promoter. Northern blots were prepared using RNAs purified from MCF7 cells that were uninduced $(-)$ or induced $(+)$ to express siRNA against RNPCla for $2 \mathrm{~d}$ and $3 \mathrm{~d}$, respectively. The blots were probed with cDNAs derived from RNPC1, p21, and GAPDH, respectively. $(B, C)$ The half-life of p21 transcript is decreased by RNPC1a knockdown. The levels of p21 and GAPDH transcripts were measured by Northern blot analysis using RNAs purified from MCF7 cells that were uninduced $(-)$ or induced $(+)$ to knock down RNPCla for $2 \mathrm{~d}$, followed by treatment with $7.5 \mu \mathrm{g} / \mathrm{mL}$ of actinomycin D (Act D) for $0,1,2,4$, or $6 \mathrm{~h}$. (D) RNPCla knockdown decreases the basal level of p21 protein in MCF7 cells. Western blots were prepared using extracts from MCF7 cells that were uninduced $(-)$ or induced $(+)$ to knock down RNPC1a for 24,48 , or $72 \mathrm{~h}$. The blots were probed with antibodies against p21, Mdm2, p53, and actin, respectively. $(E-G)$ RNPCla is necessary for the maintenance of the levels of p21 protein induced by p53 in MCF7-RNPC1a-KD-36. Western blots were prepared using extracts from MCF7 cells that were uninduced $(-)$ or induced $(+)$ to knock down RNPCla for $48 \mathrm{~h}$, followed by treatment with $0.4 \mu \mathrm{g} / \mathrm{mL}$ of doxorubincin (DOX) $(E), 5 \mu \mathrm{M}$ Nutlin $(F)$, or $300 \mathrm{nM}$ camptothecin (CPT) $(G)$ for $0-12 \mathrm{~h}$. The blots were probed with antibodies against p53, p21, Mdm2, $\mathrm{PolH}$, and actin, respectively.
A

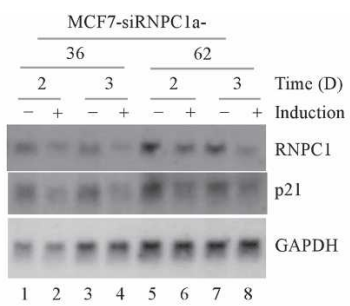

B

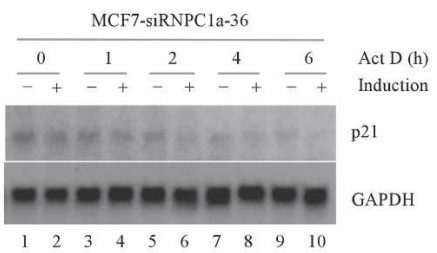

D

MCF 7-RNPC 1a-KD-36

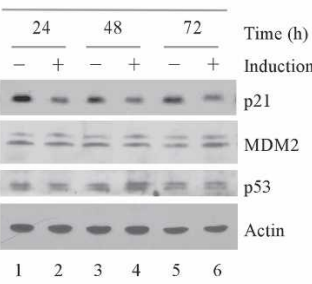

$\mathbf{F}$

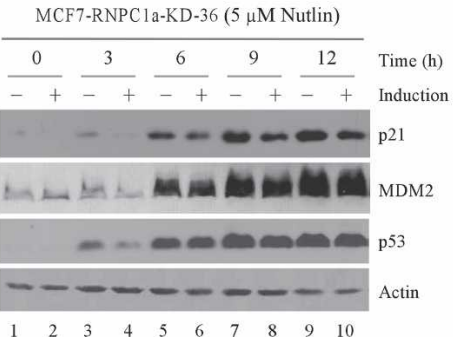

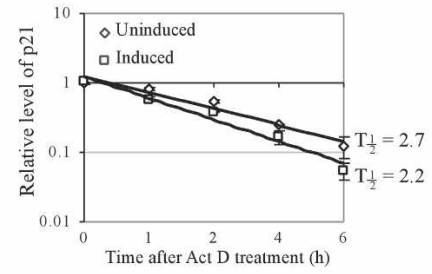

$\mathbf{E}$

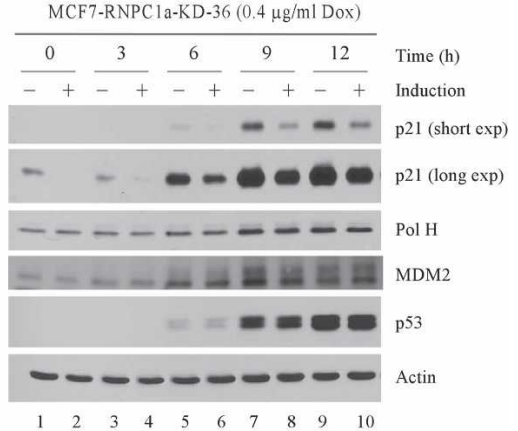

G

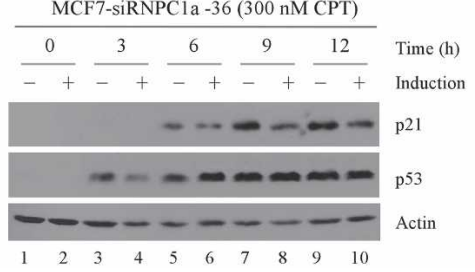

ily target gene that encodes an RNA-binding protein. Here we showed that all the p53 family members can directly transactivate RNPC1. Interestingly, when overexpressed, RNPC1a is capable of inducing cell cycle arrest in G1 at least in part via binding to and stabilizing p21 transcript. Conversely, RNPCla knockdown decreases the stability of p21 transcript. More importantly, we provided evidence that RNPCla is required for the maintenance of the stability of $\mathrm{p} 21$ transcript induced by $\mathrm{p} 53$, and overexpression of RNPC1a further increases the extent of p53 induction of p21. While the stability of p21 transcript can be regulated by HuR following UVC irradiation, the activity of HuR is controlled by its subcellular shuttling from nucleus to cytosol, which is p53 independent (Wang et al. 2000). Thus, HuR is unlikely to mediate p53-dependent stabilization of p21 transcript. As a p53 target gene, we hypothesize that RNPC1 is responsible for p53-dependent stabilization of p21 transcript, and therefore serves as both an effecter and a mediator of the p53 family in inducing cell cycle arrest in G1 (Fig. 8).

The 3' UTR in p21 transcript has been shown to contain several recognition sequences for a group of RNA- binding proteins. For example, HuR and $\mathrm{HuD}$ were found to recognize the AU-rich elements located within nucleotides 571-829 (Joseph et al. 1998; Wang et al. 2000; Giles et al. 2003; Yang et al. 2004) and Msi was found to recognize GTAGT within nucleotides 18191823 (Battelli et al. 2006). CP1 was also reported to bind to the 3' UTR (Giles et al. 2003), but its binding site has not been mapped. Here, we found that the binding region for RNPC1 is located between nucleotide 879 and 1512 , which contains several C-rich elements but lies outside the AU-rich (HuR and HuD) elements and the Msi-binding site. However, the precise nucleotide sequence remains to be determined. Since HuR and AUF1 bind to many common AU-rich target mRNAs, including p21, and exert opposing influence on target mRNA stability (Lal et al. 2004), it is possible that RNPC1 may compete and/or cooperate with other RNA-binding proteins, including HuR and Msi, to bind to their respective recognition sequences, and consequently, control the outcome for p21 mRNA stability.

We showed that both RNPC1a and RNPC1b can bind to the p 21 mRNA. This is not surprising since both isoforms contain an intact RNA-binding domain, RRM. In- 


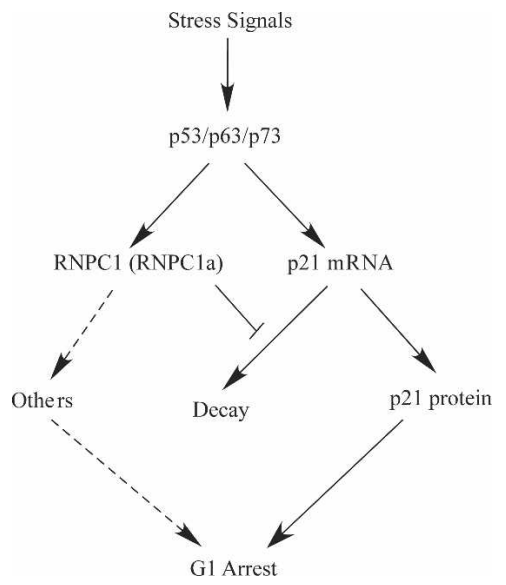

Figure 8. A model for the role of RNPC1 in the p53 family pathway to induce G1 arrest.

terestingly, we also showed that RNPC1a, but not RNPC1b, is capable of inducing cell cycle arrest and increasing the stability of p21 transcript. One possible explanation is due to the intracellular localization of these two isoforms: While both isoforms are expressed both in the nucleus and cytosol, the level of RNPC1b in the cytosol appears to be higher than that in the nucleus. Upon binding to p21 or other not yet identified transcripts, RNPC1a might facilitate their transport from nucleus to cytosol wherein protein is translated, and at the same time, further protect these transcripts from degradation by cytosolic RNases. Thus, the kinetics of p21 mRNA stability can be controlled by the stoichiometry of RNPCla versus RNPC1b. Since both isoforms contain an identical amino acid sequence in the $\mathrm{N}$ terminus, the unique 108 residues in RNPCla may interact with other proteins that together regulate p21 mRNA stability. However, RNPC1b may help RNPC1a to regulate the stability of p21 or other not yet identified transcripts. Therefore, further studies are warranted to address these potential functions of RNPC1.

Due to the nature of binding to RNA transcripts, RNA-binding proteins often display multiple functions. For example, HuR is known to regulate several early response genes, which then regulate the cell cycle and cellular differentiation (Lopez de Silanes et al. 2004). We also showed that in addition to inhibiting cell proliferation by stabilizing the $\mathrm{p} 21$ transcript, RNPC1a is able to inhibit cell proliferation in HCT116 cell line in which p21 is somatically knocked out. This suggests that RNPC1a regulates other RNA transcripts involved in the control of cell proliferation. Thus, other RNPC1 targets need to be identified in future studies, which will provide an insight into the mechanism by which RNPC1 regulates other cell cycle control pathways and other unknown functions.

\section{Materials and methods}

Plasmids

HA-tagged RNPC1a and RNPC1b were amplified by PCR using EST clone (GenBank \#BC018711) as a template with the follow- ing primers: sense primer \#1 for both isoforms, $5^{\prime}$-GAAGCTT GCCGCCATGGAGTACCCATACGACGTACCAGATTACGC TATGCTGCTGCAGCCCGCGCCG-3'; antisense primer \#2 for RNPC1a, 5'-GGAATTCTCACTGCATCCTGTCAGGCTG C-3'; and antisense primer \#3 for RNPC1b, 5'-GGAATTCT CAGCCCGTCTGGAGGCTCCGCG-3'. To generate RNPC1a (F37S), two-step PCR reactions were performed. The first-step PCR reaction was performed to separately amplify two DNA fragments: Fragment \#1, encoding the N-terminal region of RNPC1a, was amplified with the above sense primer \#1 and antisense primer \#4, 5'-TACGGCAGGCCGCCCACGGAG ATCTTGGTGAACGT-3'; and fragment \#2, encoding the Cterminal region of the RNPCla, was amplified with sense primer \#5, 5'-ACGTTCACCAAGATCTCCGTGGGCGGCCT GCCGTA-3', and the above antisense primer \#2. The secondstep PCR reaction was performed using a mixture of fragments $\# 1$ and \#2 as a template with sense primer \#1 and antisense primer \#2. These cDNAs were subcloned into pGEM T easy vector and confirmed by sequencing. A HindIII-EcoRI fragment containing the entire coding region was then purified and cloned into pcDNA3 and pcDNA4 for transient and stable inducible expressions, respectively.

To generate a construct that expresses a siRNA against RNPCla under the control of the tetracycline-regulated $\mathrm{H} 1$ promoter, two 68-base oligonucleotides targeting RNPCla were designed similarly as that for targeting p53 except that the targeting sequence is derived from RNPC1 transcript from nucleotides +568 to +588 (NM_017495) (Brummelkamp et al. 2002; Liu and Chen 2006). The pair of oligos was then annealed and cloned into pBabe-H1 at HindIII and BglII sites, and the resulting construct was designated pBabe-H1-siRNPCla. pBabe-H1 is a PolIII promoter-driven vector with a tetracycline operon sequence inserted before the transcription start site (van de Wetering et al. 2003).

To generate a luciferase reporter under the control of a potential p53RE in the RNPC1 gene, the RNPC1 promoter fragments from nucleotides -3424 to +85 (the first nucleotide upstream of the putative transcription start site is designated as -1 ) and from nucleotides -1205 to +85 were amplified by PCR and cloned separately into pGL2. The fragments were confirmed by sequencing. To generate a luciferase reporter under the control of a potential p53RE in intron 1 of the RNPC1 gene, a fragment from nucleotides +373 to +751 was amplified and cloned into the O-Fluc reporter vector upstream of a c-fos basic promoter and a luciferase reporter (Johansen and Prywes 1994). Similarly, a deletion mutant $(\Delta 520-546)$ that lacks the entire potential p53RE and a point mutant (C522A) that carries a mutation at the critical nucleotide necessary for p53 binding were generated by PCR and then separately cloned into O-Fluc. Deletion and mutation were confirmed by sequencing. pGL3 vectors that carry various regions from the $3^{\prime}$ UTR in p21 transcript were kindly provided by Drs. S. Lee and P. Leedman (Harvard Medical School, Boston, MA, and Western Australian Institute for Medical Research, Perth, Western Australia, Australia).

\section{Cell culture}

RKO, MCF7, and HCT116, were cultured in DMEM medium supplemented with fetal bovine serum. HCT116(p53 $\left.{ }^{-/}\right)$and HCT116(p21-l-) are derivatives of HCT116 in which the p53 and p21 genes were somatically knocked out, respectively (Waldman et al. 1996; Bunz et al. 1998); RKO-p53-KD is a derivative of RKO in which p53 was stably knocked down by RNA interference (RNAi) (Liu and Chen 2006). The MCF7 cell lines, which inducibly express p53, p53(R249S), p63 $\alpha, \Delta \mathrm{Np} 63 \alpha$, and p73 $\beta$, and the H1299 cell lines, which inducibly express p53, 
$\Delta \mathrm{Np} 63 \alpha$, and $\mathrm{p} 73 \beta$, were as previously described (Zhu et al. 2000; Dohn et al. 2001; Nozell et al. 2003). RKO, MCF7,

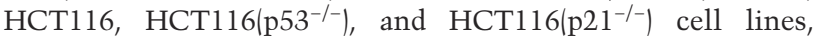
which inducibly express HA-tagged RNPC1a or RNPC1b, were generated as previously described (Dohn et al. 2003). To generate inducible RNPCla knockdown cell lines, pBabe-H1siRNPC1a was transfected into MCF7 cells in which a tetracycline repressor is expressed by pcDNA6 (Yan and Chen 2006). The RNPCla knockdown cell lines were selected with puromycin and confirmed by Northern blot analysis.

\section{Luciferase assay}

A dual luciferase assay was performed in triplicate according to the manufacturer's instructions (Promega). Briefly, p53-null H1299 cells were plated at $5 \times 10^{4}$ cells per well in a 24 -well plate and allowed to recover overnight. Cells were then cotransfected with $200 \mathrm{ng}$ each of pGL2, O-Fluc, or pGL3 together with pcDNA3 or a pcDNA3 vector expressing wild-type p53, mutant p53(R249S), p63, p73, or RNPC1a. As an internal control, $5 \mathrm{ng}$ of pRL-CMV, a Renilla luciferase vector (Promega), was also cotransfected per well. Thirty-six hours post-transfection, luciferase activity was measured with the dual luciferase kit and Turner Designs luminometer. The fold increase in relative luciferase activity is a product of the luciferase activity induced by a p53 family protein or RNPC1a divided by that induced by empty pcDNA3 vector.

\section{ChIP assay}

ChIP assay was performed as previously described (Liu et al. 2003; Harms and Chen 2005). RKO cells were mock-treated or treated with doxorubicin for $24 \mathrm{~h}$, whereas MCF7 cells were uninduced or induced to express Myc-tagged p63 $\gamma$ or HA-tagged p $73 \beta$ for $24 \mathrm{~h}$. Chromatins in these cells were then cross-linked with $1 \%$ formaldehyde for $10 \mathrm{~min}$ at room temperature, sonicated to generate 500- to 1000-bp DNA fragments, and immunoprecipitated with anti-p53 antibody to capture p53-DNA complexes, with anti-myc antibody to capture myc-tagged p63 $\gamma$-DNA complexes, or with anti-HA antibody to capture HA-tagged p $73 \beta$-DNA complexes. After reverse cross-linking and phenol-chloroform extraction, the bound DNA fragments were purified by a Qiagen column. PCR was performed to visualize the enriched DNA fragments. The primers designed to amplify the p53RE within the RNPC1 promoter were sense, 5'-CAGCACACACAGTTGCCAGTCC-3' ${ }^{\prime}$, and antisense, $5^{\prime}$ CTTAGGTATCAGCTGACTGCCAAGG-3'. The primers designed to amplify the p53RE within intron 1 of the RNPC1 gene were sense, 5' ${ }^{\prime}$-TTCCAAGCATAGCGTCGCAAACTC-3', and antisense, 5'-CTCCTCCCGTCAAAGTTCAAGGC-3'. The primers designed to amplify the upstream p53RE within the p21 promoter were as previously described (Liu et al. 2003).

\section{DNA histogram analysis}

Cells induced or uninduced to express or knock down RNPC1 for various times were collected and fixed in $75 \%$ ethanol for at least $1 \mathrm{~h}$ at $4^{\circ} \mathrm{C}$. Cells were then washed with PBS and resuspended in staining buffer with $100 \mu \mathrm{g} / \mathrm{mL}$ RNase A and $50 \mu \mathrm{g} /$ $\mathrm{mL}$ propidium iodine (Invitrogen). The percentage of cells in each phase of the cell cycle (G1, S, and G2-M) was analyzed by a FACS-Caliber cell sorter (BD Biosciences) along with CellQuest software.

\section{Northern blot analysis}

Total RNAs were isolated from H1299, RKO, MCF7, and HCT116 cells using Trizol reagent (Invitrogen). Northern blot analysis and preparation of $\mathrm{p} 21$ and GAPDH probes were as described previously (Chen et al. 1995). The RNPC1 probe, a 2.1-kb Xho1-EcoR1 fragment, was made from an EST clone (BC018711).

\section{Antibody production and immunoblotting}

To prepare anti-RNPC1 antibody, the full-length RNPC1a was cloned into a pRSet-A bacterial expression vector (Invitrogen). His-tagged RNPC1 protein was expressed in bacteria and purified with Ni-agarose beads. Anti-RNPC1 antibody was raised in two rabbits. For immunoblotting, cells were collected from culture plates in PBS, resuspended in $2 \times$ sample buffer, and boiled for $7 \mathrm{~min}$ at $95^{\circ} \mathrm{C}$. Anti-RNPC1 antibody was diluted in PBST containing $5 \%$ BSA instead of $5 \%$ dry milk. Other antibodies used were anti-p53 monoclonal antibodies (DO-1, PAb1801, PAb240, and PAb421); anti-actin (Sigma); anti-p21 (C-19) (Santa Cruz Biotechnology); anti-PCNA (Santa Cruz Biotechnology); anti-Mdm2 (Santa Cruz Biotechnology); anti-PolH (Santa Cruz Biotechnology); anti-HA monoclonal antibodies (12CA5 and HA11) (Covance); and anti-Myc monoclonal antibody (9E10) (Cell Signaling).

\section{Coimmunoprecipitation and RT-PCR}

RKO cells that were transfected with a pcDNA3 vector expressing HA-tagged RNPC1a, RNPC1a (F37S), or RNPC1b for $24 \mathrm{~h}$ were collected and lysed at $4^{\circ} \mathrm{C}$ with a lysis buffer $(50 \mathrm{mM}$ Tris- $\mathrm{HCl}$ at $\mathrm{pH}$ 7.4, $1 \% \mathrm{NP}-40,150 \mathrm{mM} \mathrm{NaCl}, 10 \mu \mathrm{g} / \mathrm{mL}$ aprotinin, $10 \mu \mathrm{g} / \mathrm{mL}$ leupeptin, $1 \mathrm{mM}$ PMSF, $2 \mathrm{mM}$ Na3VO4, $50 \mathrm{mM}$ $\mathrm{NaF}, 0.5 \mathrm{U} / \mu \mathrm{l}$ RNasin). Five percent of the cell extracts were used directly for total RNA isolation, and the remaining extracts were incubated with protein $\mathrm{A} / \mathrm{G}$ beads conjugated with anti-HA or anti-Flag antibody (Sigma) overnight. Following four washes with a buffer containing RNase-free DNase, RNAs on the beads were purified with a Trizol reagent. Reverse transcription was performed using iScript (Bio-Rad). To avoid potential genomic DNA contamination, both sense primer, 5'-ATGT CAGAACCGGCTGGGGATG-3', and antisense primer, $5^{\prime}$ TTAGGGCTTCCTCTTGGAGAAGATCA-3', were designed to amplify the entire p21 ORF $\left(1 \mathrm{~min}\right.$ at $94^{\circ} \mathrm{C}, 30 \mathrm{sec}$ at $55^{\circ} \mathrm{C}$, and $1 \mathrm{~min}$ at $72^{\circ} \mathrm{C}$ for 35 cycles). The primers used to amplify GAPDH transcripts were forward primer, 5'-TGAAGGTCG GAGTCAACGGATTTGGT-3', and reverse primer, 5'-CATGT GGGCCATGAGGTCCACCAC-3'.

\section{Acknowledgments}

We thank Anita Chen for technical assistance, Kelly Harms for the MCF7 tet-on cell line, and Gang Liu, Jin Zhang, Ariane Scoummane, Scott Helton, Yingquan Qian, and Yang Xu for suggestions. This work is supported in part by NIH grants.

\section{References}

Barak, Y., Juven, T., Haffner, R., and Oren, M. 1993. mdm2 expression is induced by wild type p53 activity. EMBO I. 12: 461-468.

Battelli, C., Nikopoulos, G.N., Mitchell, J.G., and Verdi, J.M. 2006. The RNA-binding protein Musashi-1 regulates neural development through the translational repression of p21WAF-1. Mol. Cell. Neurosci. 31: 85-96.

Brummelkamp, T.R., Bernards, R., and Agami, R. 2002. A system for stable expression of short interfering RNAs in mammalian cells. Science 296: 550-553. 
Buckbinder, L., Talbott, R., Velasco-Miguel, S., Takenaka, I., Faha, B., Seizinger, B.R., and Kley, N. 1995. Induction of the growth inhibitor IGF-binding protein 3 by p53. Nature 377: 646-649.

Bunz, F., Dutriaux, A., Lengauer, C., Waldman, T., Zhou, S., Brown, J.P., Sedivy, J.M., Kinzler, K.W., and Vogelstein, B. 1998. Requirement for p53 and p21 to sustain G2 arrest after DNA damage. Science 282: 1497-1501.

Chen, X., Bargonetti, J., and Prives, C. 1995. p53, through p21 (WAF1/CIP1), induces cyclin D1 synthesis. Cancer Res. 55: 4257-4263.

Chen, X., Liu, G., Zhu, J., Jiang, J., Nozell, S., and Willis, A. 2003. Isolation and characterization of fourteen novel putative and nine known target genes of the p53 family. Cancer Biol. Ther. 2: 55-62.

Dohn, M., Zhang, S., and Chen, X. 2001. p63 $\alpha$ and $\Delta$ Np63 $\alpha$ can induce cell cycle arrest and apoptosis and differentially regulate p53 target genes. Oncogene 20: 3193-3205.

Dohn, M., Nozell, S., Willis, A., and Chen, X. 2003. Tumor suppressor gene-inducible cell lines. Methods Mol. Biol. 223: 221-235.

Dreyfuss, G., Matunis, M.J., Pinol-Roma, S., and Burd, C.G. 1993. hnRNP proteins and the biogenesis of mRNA. Annu. Rev. Biochem. 62: 289-321.

Dreyfuss, G., Kim, V.N., and Kataoka, N. 2002. MessengerRNA-binding proteins and the messages they carry. Nat. Rev. Mol. Cell Biol. 3: 195-205.

el-Deiry, W.S., Kern, S.E., Pietenpol, J.A., Kinzler, K.W., and Vogelstein, B. 1992. Definition of a consensus binding site for p53. Nat. Genet. 1: 45-49.

el-Deiry, W.S., Tokino, T., Velculescu, V.E., Levy, D.B., Parsons, R., Trent, J.M., Lin, D., Mercer, W.E., Kinzler, K.W., and Vogelstein, B. 1993. WAF1, a potential mediator of p53 tumor suppression. Cell 75: 817-825.

Giles, K.M., Daly, J.M., Beveridge, D.J., Thomson, A.M., Voon, D.C., Furneaux, H.M., Jazayeri, J.A., and Leedman, P.J. 2003. The 3 '-untranslated region of $\mathrm{p} 21 \mathrm{WAF} 1 \mathrm{mRNA}$ is a composite cis-acting sequence bound by RNA-binding proteins from breast cancer cells, including HuR and poly(C)-binding protein. J. Biol. Chem. 278: 2937-2946.

Gorospe, M. 2003. HuR in the mammalian genotoxic response: Post-transcriptional multitasking. Cell Cycle 2: 412-414.

Gorospe, M. and Holbrook, N.J. 1996. Role of p21 in prostaglandin A2-mediated cellular arrest and death. Cancer Res. 56: 475-479.

Gorospe, M., Wang, X., and Holbrook, N.J. 1998. p53-dependent elevation of p21Waf1 expression by UV light is mediated through mRNA stabilization and involves a vanadate-sensitive regulatory system. Mol. Cell. Biol. 18: 1400-1407.

Harms, K.L. and Chen, X. 2005. The C terminus of p53 family proteins is a cell fate determinant. Mol. Cell. Biol. 25: 20142030.

Harms, K., Nozell, S., and Chen, X. 2004. The common and distinct target genes of the p53 family transcription factors. Cell. Mol. Life Sci. 61: 822-842.

Harper, J.W., Adami, G.R., Wei, N., Keyomarsi, K., and Elledge, S.J. 1993. The p21 Cdk-interacting protein Cip1 is a potent inhibitor of G1 cyclin-dependent kinases. Cell 75: 805-816.

Johansen, F.E. and Prywes, R. 1994. Two pathways for serum regulation of the c-fos serum response element require specific sequence elements and a minimal domain of serum response factor. Mol. Cell. Biol. 14: 5920-5928.

Joseph, B., Orlian, M., and Furneaux, H. 1998. p21(waf1) mRNA contains a conserved element in its $3^{\prime}$-untranslated region that is bound by the Elav-like mRNA-stabilizing proteins. $J$. Biol. Chem. 273: 20511-20516.
Kaghad, M., Bonnet, H., Yang, A., Creancier, L., Biscan, J.C., Valent, A., Minty, A., Chalon, P., Lelias, J.M., Dumont, X., et al. 1997. Monoallelically expressed gene related to p53 at $1 \mathrm{p} 36$, a region frequently deleted in neuroblastoma and other human cancers. Cell 90: 809-819.

Ko, L.J. and Prives, C. 1996. p53: Puzzle and paradigm. Genes \& Dev. 10: 1054-1072.

Krecic, A.M. and Swanson, M.S. 1999. hnRNP complexes: Composition, structure, and function. Curr. Opin. Cell Biol. 11: 363-371.

Lal, A., Mazan-Mamczarz, K., Kawai, T., Yang, X., Martindale, J.L., and Gorospe, M. 2004. Concurrent versus individual binding of HuR and AUF1 to common labile target mRNAs. EMBO T. 23: 3092-3102.

Lin, Y., Ma, W., and Benchimol, S. 2000. Pidd, a new deathdomain-containing protein, is induced by p53 and promotes apoptosis. Nat. Genet. 26: 122-127.

Liu, G. and Chen, X. 2006. DNA polymerase eta, the product of the xeroderma pigmentosum variant gene and a target of p53, modulates the DNA damage checkpoint and p53 activation. Mol. Cell. Biol. 26: 1398-1413.

Liu, Y., Martindale, J.L., Gorospe, M., and Holbrook, N.J. 1996. Regulation of p21WAF1/CIP1 expression through mitogenactivated protein kinase signaling pathway. Cancer Res. 56: 31-35.

Liu, G., Xia, T., and Chen, X. 2003. The activation domains, the proline-rich domain, and the C-terminal basic domain in $\mathrm{p} 53$ are necessary for acetylation of histones on the proximal p21 promoter and interaction with p300/CREB-binding protein. J. Biol. Chem. 278: 17557-17565.

Lopez de Silanes, I., Zhan, M., Lal, A., Yang, X., and Gorospe, M. 2004. Identification of a target RNA motif for RNA-binding protein HuR. Proc. Natl. Acad. Sci. 101: 2987-2992.

Myer, V.E., Fan, X.C., and Steitz, J.A. 1997. Identification of HuR as a protein implicated in AUUUA-mediated mRNA decay. $E M B O$ I. 16: 2130-2139.

Nozell, S., Wu, Y., McNaughton, K., Liu, G., Paik, J., and Chen, X. 2003. Characterization of $\mathrm{p} 73$ functional domains necessary for growth suppression. Oncogene 22: 4333-4347.

Shiohara, M., Akashi, M., Gombart, A.F., Yang, R., and Koeffler, H.P. 1996. Tumor necrosis factor $\alpha$ : Posttranscriptional stabilization of WAF1 mRNA in p53-deficient human leukemic cells. J. Cell. Physiol. 166: 568-576.

Siomi, H., Siomi, M.C., Nussbaum, R.L., and Dreyfuss, G. 1993. The protein product of the fragile $\mathrm{X}$ gene, FMR1, has characteristics of an RNA-binding protein. Cell 74: 291-298.

Timchenko, L.T., Miller, J.W., Timchenko, N.A., DeVore, D.R., Datar, K.V., Lin, L., Roberts, R., Caskey, C.T., and Swanson, M.S. 1996. Identification of a (CUG)n triplet repeat RNAbinding protein and its expression in myotonic dystrophy. Nucleic Acids Res. 24: 4407-4414.

van de Wetering, M., Oving, I., Muncan, V., Pon Fong, M.T., Brantjes, H., van Leenen, D., Holstege, F.C., Brummelkamp, T.R., Agami, R., and Clevers, H. 2003. Specific inhibition of gene expression using a stably integrated, inducible smallinterfering-RNA vector. EMBO Rep. 4: 609-615.

Vassilev, L.T., Vu, B.T., Graves, B., Carvajal, D., Podlaski, F., Filipovic, Z., Kong, N., Kammlott, U., Lukacs, C., Klein, C., et al. 2004. In vivo activation of the p53 pathway by smallmolecule antagonists of MDM2. Science 303: 844-848.

Vogelstein, B., Lane, D., and Levine, A.J. 2000. Surfing the p53 network. Nature 408: 307-310.

Vousden, K.H. and Lu, X. 2002. Live or let die: The cell's response to p53. Nat. Rev. Cancer 2: 594-604.

Waldman, T., Lengauer, C., Kinzler, K.W., and Vogelstein, B. 1996. Uncoupling of $S$ phase and mitosis induced by anti- 
Shu et al.

cancer agents in cells lacking p21. Nature 381: 713-716.

Wang, W., Furneaux, H., Cheng, H., Caldwell, M.C., Hutter, D., Liu, Y., Holbrook, N., and Gorospe, M. 2000. HuR regulates p21 mRNA stabilization by UV light. Mol. Cell. Biol. 20: 760-769.

Wu, X., Bayle, J.H., Olson, D., and Levine, A.J. 1993. The p53mdm-2 autoregulatory feedback loop. Genes \& Dev. 7: 11261132 .

Wu, G.S., Burns, T.F., McDonald III, E.R., Jiang, W., Meng, R., Krantz, I.D., Kao, G., Gan, D.D., Zhou, J.Y., Muschel, R., et al. 1997. KILLER/DR5 is a DNA damage-inducible p53-regulated death receptor gene. Nat. Genet. 17: 141-143.

Xiong, Y., Hannon, G.J., Zhang, H., Casso, D., Kobayashi, R., and Beach, D. 1993. p21 is a universal inhibitor of cyclin kinases. Nature 366: 701-704.

Yan, W. and Chen, X. 2006. GPX2, a direct target of p63, inhibits oxidative stress-induced apoptosis in a p53-dependent manner. J. Biol. Chem. 281: 7856-7862.

Yang, A., Kaghad, M., Wang, Y., Gillett, E., Fleming, M.D., Dotsch, V., Andrews, N.C., Caput, D., and McKeon, F. 1998. p63, a p53 homolog at 3q27-29, encodes multiple products with transactivating, death-inducing, and dominant-negative activities. Mol. Cell 2: 305-316.

Yang, X., Wang, W., Fan, J., Lal, A., Yang, D., Cheng, H., and Gorospe, M. 2004. Prostaglandin A2-mediated stabilization of p21 mRNA through an ERK-dependent pathway requiring the RNA-binding protein HuR. J. Biol. Chem. 279: 4929849306.

Zhu, J., Jiang, J., Zhou, W., and Chen, X. 1998. The potential tumor suppressor p73 differentially regulates cellular p53 target genes. Cancer Res. 58: 5061-5065.

Zhu, J., Zhang, S., Jiang, J., and Chen, X. 2000. Definition of the p53 functional domains necessary for inducing apoptosis. $J$. Biol. Chem. 275: 39927-39934. 


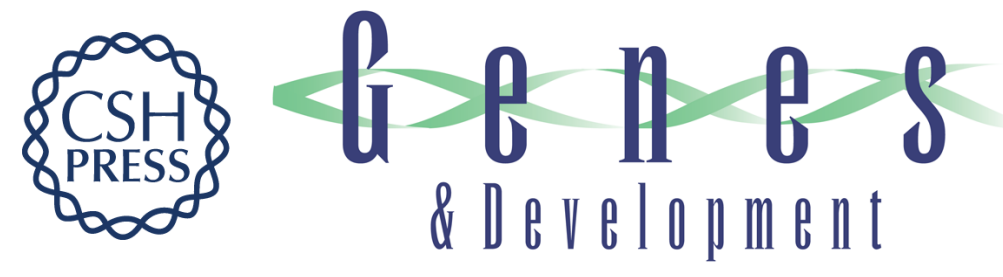

\section{RNPC1, an RNA-binding protein and a target of the p53 family, is required for maintaining the stability of the basal and stress-induced p21 transcript}

Limin Shu, Wensheng Yan and Xinbin Chen

Genes Dev. 2006, 20: originally published online October 18, 2006

Access the most recent version at doi:10.1101/gad.1463306

Supplemental Material

References

License

Email Alerting

Service
http://genesdev.cshlp.org/content/suppl/2006/10/17/gad.1463306.DC1

This article cites 50 articles, 24 of which can be accessed free at: http://genesdev.cshlp.org/content/20/21/2961.full.html\#ref-list-1

Receive free email alerts when new articles cite this article - sign up in the box at the top right corner of the article or click here.

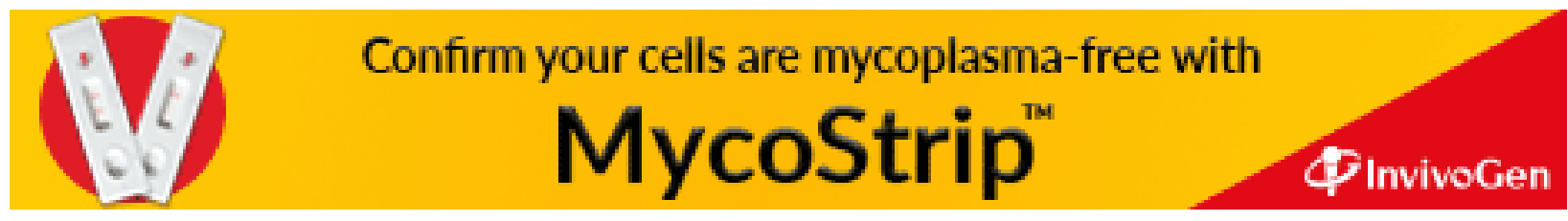

